This article is licensed under the Creative Commons Attribution-NonCommercial 4.0 International License (CC BY-NC) (http://www.karger.com/Services/OpenAccessLicense). Usage and distribution for commercial purposes requires written permission.

\title{
A Case of Gastric Antral Vascular Ectasia Which Was Aggravated by Acid Reducer
}

\author{
Yukiomi Nakade $^{\mathrm{a}}$ Tomonori Ozeki $^{\mathrm{b}}$ Hiroyuki Kanamori ${ }^{\mathrm{a}}$ \\ Tadahisa Inoue $^{a} \quad$ Takaya Yamamoto $^{a}$ Yuji Kobayashi ${ }^{a}$ Norimitsu Ishii ${ }^{a}$ \\ Tomohiko Ohashi $^{\mathrm{a}}$ Kiyoaki Ito ${ }^{\mathrm{a}}$ Masashi Yoneda $^{\mathrm{a}}$ \\ ${ }^{a}$ Division of Gastroenterology, Department of Internal Medicine, Aichi Medical University, \\ Nagakute, Japan; ${ }^{b}$ Division of Gastroenterology, Nagoya City West Medical Center, \\ Nagoya, Japan
}

\section{Keywords}

Gastric antral vascular ectasia · Acid reducer - Gastrointestinal hemorrhage · Oozing · Argon plasma laser coagulation

\begin{abstract}
Gastric antral vascular ectasia (GAVE) is known to be characterized by red patches or spots in a diffuse or linear array in the antrum of the stomach. The precise etiology of GAVE remains to be elucidated. Argon plasma laser coagulation (APC) has been used to control oozing from GAVE; however, there is no satisfactory long-term effect of APC in the control of oozing from GAVE. An acid reducer is used after APC because even physiological acid exposure might delay post-APC ulcer healing. We describe the case of a patient who had used an acid reducer and experienced repeated gastrointestinal hemorrhage due to GAVE. After ceasing to administer the acid reducer, incidences of hospitalization due to oozing from GAVE stopped. After the administration of the acid reducer was restarted, the patient had tarry stool, and diffuse oozing of blood was seen again. We report a first case of GAVE which was aggravated by acid reducer.




\section{Case Reports in Gastroenterology}

Case Rep Gastroenterol 2017;11:64-71

DOI: $10.1159 / 000455967$

(C) 2017 The Author(s). Published by S. Karger AG, Basel www.karger.com/crg

Nakade et al.: A Case of Gastric Antral Vascular Ectasia Which Was Aggravated by Acid Reducer

\section{Introduction}

Gastric antral vascular ectasia (GAVE) is known to be characterized by red patches or spots in a diffuse or linear array in the antrum of the stomach [1]. GAVE can be associated with gastrointestinal (GI) hemorrhage in patients with liver cirrhosis and portal hypertension [1,2]. Although about $30 \%$ of patients with GAVE have liver cirrhosis, more than $70 \%$ of these patients are free of liver cirrhosis [3]. The mechanical stress, gastric motility dysfunction, and neurohormonal factors are thought to be involved in the etiology of GAVE; however, a precise mechanism for GAVE remains to be elucidated $[4,5]$.

Several therapeutic approaches have been used for the treatment of GI hemorrhage from GAVE. Argon plasma laser coagulation (APC) has been found to stop oozing; however, it is not as effective in patients with diffuse GAVE [6]. There is no satisfactory long-term effect of APC in the control of oozing from GAVE [7]. Some authors advocate an acid reducer after APC because physiological acid exposure might delay a post-APC ulcer healing [8]. Pantoprazole, a proton pump inhibitor (PPI), reduces the size of postendoscopic band ligation ulcers; however, the long-term effect of PPI for GAVE treated with APC remains to be elucidated [9].

Here, we describe a case of GAVE in a patient with repeated GI hemorrhage treated with APC. After long-time prescription of acid reducer, hospitalizations for oozing due to GAVE continued. Following the termination of PPI administration, hospitalizations for oozing due to GAVE stopped. We report a case where cessation of acid reducer possibly contributed to the attenuation of oozing due to GAVE.

\section{Case Presentation}

A 76-year-old woman diagnosed with liver cirrhosis due to chronic hepatitis type $C$ in the department of gastroenterology in our hospital at the age of 65 years was examined for tarry stool at a follow-up visit on December 6, 2007. She had a history of blood transfusion due to surgery for uterine myoma at the age of 49 years. She had been diagnosed with CREST syndrome at the age of 67 years. No remarkable familial history existed. On physical examination, her height was $145 \mathrm{~cm}$ and her body weight was $39 \mathrm{~kg}$. Her palpebral conjunctiva was anemic and her bulbar conjunctiva showed no icterus, and heart and respiratory sounds were normal. Her liver and spleen were not palpable. Her lower arms and fingers were taut. Raynaud's phenomenon and telangiectasia were not evident. Laboratory workup revealed that red blood cell count was $2.0 \times 10^{6} / \mathrm{mL}$, hemoglobin level was $6.0 \mathrm{~g} / \mathrm{dL}$, and platelet count was $14.0 \times 10^{4} / \mathrm{mL}$. Serum aspartate aminotransferase and alanine aminotransferase levels were elevated; however, serum albumin, total cholesterol, and triglyceride levels were attenuated (Table 1). Her Child-Pugh score was B. The clinical course is presented in Figure 1. We performed an upper GI endoscopy to examine the focus of the tarry stool. Endoscopic findings showed red patches or spots in a diffuse or linear array in the antrum of the stomach, and oozing of blood (Fig. 2a). She also had atrophic gastritis, and Helicobacter pylori infection was not detected. APC was performed to stop the oozing from GAVE (Fig. 2b). After that we administered nizatidine (300 mg), a histamine H2 receptor antagonist (H2RA), to prevent post-APC ulcer expansion. In March, June, and September 2008 , the patient repeatedly experienced progression of anemia and tarry stool due to the 


\section{Case Reports in Gastroenterology}

Case Rep Gastroenterol 2017;11:64-71

DOI: $10.1159 / 000455967$

(C)

(C) 2017 The Author(s). Published by S. Karger AG, Basel www.karger.com/crg

Nakade et al.: A Case of Gastric Antral Vascular Ectasia Which Was Aggravated by Acid Reducer

oozing of blood from GAVE (Fig. 2c). APC and blood transfusion were repeatedly performed, with the patient subsequently experiencing gastroesophageal reflux symptoms; the prescription was changed from nizatidine to omeprazole $(20 \mathrm{mg})$, a PPI. Even thereafter, the patient repeatedly had oozing of blood from GAVE, and APC was repeatedly performed and omeprazole had been continuously administered. The patient was admitted to hospital 8 times from September 2008 until August 2010.

As the number of hospitalizations had not decreased after the prescription was changed from nizatidine to omeprazole, we stopped prescribing omeprazole in August 2010. After that, no acid reducers were administered, and the patient did not experience anemia and tarry stool. In November 2011, upper GI endoscopy showed improvement of the red patches or spots in the antrum of the stomach (Fig. 3a).

In June 2012, the patient had a sensation of pressure in the esophagus, and we performed upper GI endoscopy. Endoscopic images showed that a gastric ulcer had emerged on the gastric angle of the greater curvature (Fig. 3b). We prescribed esomeprazole (20 mg), a PPI for gastric ulcer. As the patient had a sensation of pressure in the esophagus even after the ulcer healing, the administration of esomeprazole was continued long term. In March 2013, the patient exhibited anemia and tarry stool. Upper GI endoscopy revealed small and flat red spots in the antrum (Fig. 3c). The patient was then admitted to our hospital, and APC and blood transfusion were performed. On her admission, her serum gastrin level was 800 IU/L. After stopping PPI treatment, her serum gastrin levels decreased to $150 \mathrm{IU} / \mathrm{L}$, which was within the normal range. After that, her condition stabilized, and no oozing from GAVE was evident. Follow-up upper GI endoscopy showed that red patches or spots were attenuated in the antrum of the stomach (Fig. 3d).

\section{Discussion}

GAVE is frequently associated with GI blood loss in patients with and without liver cirrhosis [10]. The features of GAVE include red patches or spots in a diffuse or linear array and often the presence of hemorrhagic lesions predominantly located in the gastric antrum [1]. GAVE is also referred to as "watermelon stomach", and an uncommon cause of chronic GI bleeding [1]. Although approximately $30 \%$ of patients with GAVE have cirrhosis, the natural history of GAVE is not completely understood [2]. In the present case, a patient with GAVE had liver cirrhosis due to chronic hepatitis type $C$ as well as CREST syndrome. Among 45 consecutive patients with GAVE who had been treated by endoscopic laser coagulation, 71\% were women [11]. Autoimmune connective tissue disorders were present in $62 \%$ patients, including $31 \%$ with Raynaud's phenomenon and $20 \%$ with sclerodactylia [11].

The pathology of GAVE suggests that it is acquired ectasia rather than a congenital anomaly. Some research advocates the potential involvement of mechanical stress based on the mucosal findings of GAVE, because histological features are similar to those found in intussusception or mucosal trauma [1]. Another focus is on vasoactive substances, such as vasoactive intestinal peptide and 5-hydroxytryptamine, which are found close to the vessels in the lamina propria of respective specimens from patients with GAVE. It remains unclear whether mechanical stress and hormonal factors are involved in the mechanism of ectasia from GAVE. The gastric antral motility of those with GAVE was reported to be decreased 
compared to that in patients without GAVE but with cirrhosis. The occurrence of GAVE in cirrhosis might be related to the involvement in gastric antral motility dysfunction [4]. Furthermore, patients with CREST syndrome have esophageal motor dysfunction. In the present case, since the patient had a sensation of pressure in the esophagus, esophageal motor dysfunction might be involved in the pathophysiology of GAVE.

Previous research has shown that patients with CREST syndrome are at risk of developing severe GI hemorrhage, and mucosal telangiectasias were the most common cause of bleeding [12]. During the administration of H2RA or PPI, the patient had tarry stool, and diffuse oozing of blood was seen. After the prescription and administration of PPI were terminated, the patient did not experience anemia and tarry stool, and upper GI endoscopy revealed that the red patches or spots in the antrum of the stomach had decreased. After the administration of PPI was restarted, the patient again had tarry stool, and diffuse oozing of blood was seen. These results indicated that the acid reducer plays an important role in GI hemorrhage from GAVE. Previous reports showed that gastrin and prostaglandin have been implicated in the development of GAVE owing to their presence in increased amounts in serum and the gastric mucosa in those with GAVE, as well as their local vasodilatory properties, particularly prostaglandin E [13]. In the present case, the serum gastrin level was increased during the administration of PPI. On the other hand, after cessation of PPI, the serum gastrin level decreased. Previous reports demonstrated that serum gastrin levels significantly increased in cirrhotic patients with multiple gastric red spots compared with those without multiple gastric red spots in GAVE [10]. PPI cessation may decrease serum gastrin levels resulting in the remission of GAVE. Previous reports indicate that GAVE severity was not reported to be correlated with liver function. In our case, repeated gastric hemorrhage reduced serum albumin levels; however, the patient's liver function was not remarkably changed compared with that before oozing from GAVE. Thus, liver function in cirrhosis might not be involved in oozing from GAVE.

In conclusion, we describe a case of GAVE with treatment with H2RA or PPI and repeated GI hemorrhage. After the cessation of PPI, GAVE improved. After the administration of PPI was restarted, GAVE aggravated. PPI cessation might contribute both to the reduction of serum gastrin levels and the resolution of oozing due to GAVE.

\section{Statement of Ethics}

Consent was obtained from the patient for the publication of this case report.

\section{Disclosure Statement}

All authors declare no conflicts of interest. 


\section{Case Reports in \\ Gastroenterology}

Case Rep Gastroenterol 2017;11:64-71

DOI: $10.1159 / 000455967$

(C) 2017 The Author(s). Published by S. Karger AG, Base www.karger.com/crg

Nakade et al.: A Case of Gastric Antral Vascular Ectasia Which Was Aggravated by Acid Reducer

\section{References}

1 Jabbari M, Cherry R, Lough JO, Daly DS, Kinnear DG, Goresky CA: Gastric antral vascular ectasia: the watermelon stomach. Gastroenterology 1984;87:1165-1170.

2 Burak KW, Lee SS, Beck PL: Portal hypertensive gastropathy and gastric antral vascular ectasia (GAVE) syndrome. Gut 2001;49:866-872.

-3 Payen JL, Calès P: Gastric modifications in cirrhosis (in French). Gastroenterol Clin Biol 1991;15:285295.

4 Charneau J, Petit R, Calès P, Dauver A, Boyer J: Antral motility in patients with cirrhosis with or without gastric antral vascular ectasia. Gut 1995;37:488-492.

5 Lowes JR, Rode J: Neuroendocrine cell proliferations in gastric antral vascular ectasia. Gastroenterology 1989;97:207-212.

6 Probst A, Scheubel R, Wienbeck M: Treatment of watermelon stomach (GAVE syndrome) by means of endoscopic argon plasma coagulation (APC): long-term outcome. Z Gastroenterol 2001;39:447-452. Roman S, Saurin JC, Dumortier J, Perreira A, Bernard G, Ponchon T: Tolerance and efficacy of argon plasma coagulation for controlling bleeding in patients with typical and atypical manifestations of watermelon stomach. Endoscopy 2003;35:1024-1028.

Boo GB, Oh JC, Lee BJ, Lee DM, Kim YD, Park CG, Kim MW: The effect of proton pump inhibitor on healing of post-esophageal variceal ligation ulcers (in Korean). Korean J Gastroenterol 2008;51:232240.

9 Shaheen NJ, Stuart E, Schmitz SM, Mitchell KL, Fried MW, Zacks S, Russo MW, Galanko J, Shrestha R: Pantoprazole reduces the size of postbanding ulcers after variceal band ligation: a randomized, controlled trial. Hepatology 2005;41:588-594.

$\checkmark 10$ Quintero E, Pique JM, Bombi JA, Bordas JM, Sentis J, Elena M, Bosch J, Rodes J: Gastric mucosal vascular ectasias causing bleeding in cirrhosis. A distinct entity associated with hypergastrinemia and low serum levels of pepsinogen I. Gastroenterology 1987;93:1054-1061.

11 Gostout CJ, Viggiano TR, Ahlquist DA, Wang KK, Larson MV, Balm R: The clinical and endoscopic spectrum of the watermelon stomach. J Clin Gastroenterol 1992;15:256-263.

12 Duchini A, Sessoms SL: Gastrointestinal hemorrhage in patients with systemic sclerosis and CREST syndrome. Am J Gastroenterol 1998;93:1453-1456.

13 Saperas E, Perez Ayuso RM, Poca E, Bordas JM, Gaya J, Pique JM: Increased gastric PGE2 biosynthesis in cirrhotic patients with gastric vascular ectasia. Am J Gastroenterol 1990;85:138-144. 


\section{Case Reports in Gastroenterology}

Nakade et al.: A Case of Gastric Antral Vascular Ectasia Which Was Aggravated by Acid
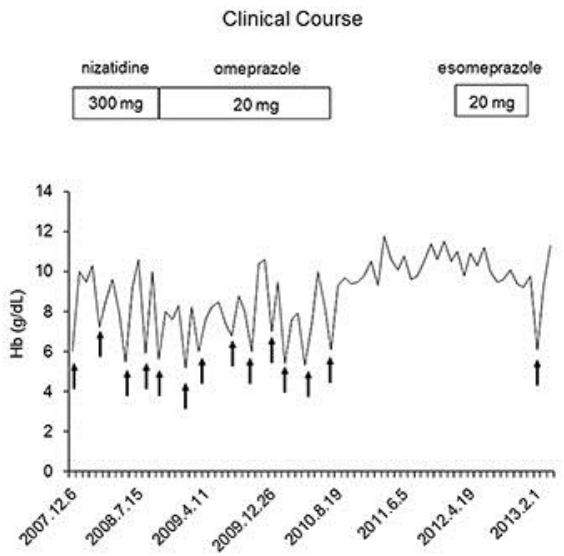

Fig. 1. Clinical course of the patient with GAVE experiencing oozing and treated by APC and blood transfusion. Arrows indicate hospitalizations.
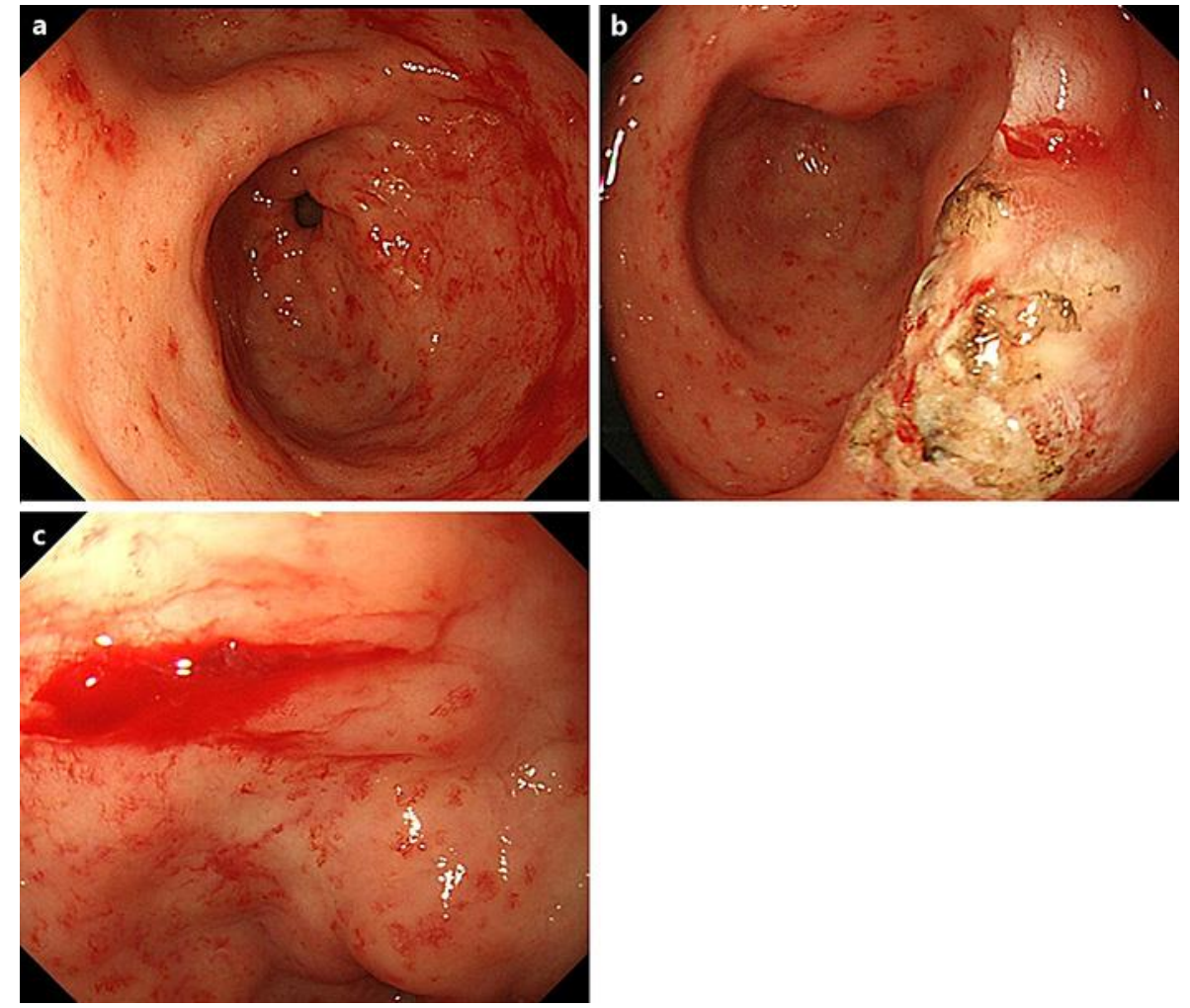

Fig. 2. a Endoscopic appearance of red patches or spots in a diffuse or linear array in the antrum of the stomach and oozing of blood. $\mathbf{b}$ Endoscopic appearance of gastric erosion emerged in the antrum after APC. c Endoscopic appearance of multiple columns of tortuous ectatic vessels with oozing in the antrum of the stomach. 


\section{Case Reports in Gastroenterology}

\begin{tabular}{l|l} 
Case Rep Gastroenterol 2017;11:64-71 \\
\hline DOI: 10.1159/000455967 & $\begin{array}{l}\text { ( 2 2017 The Author(s). Published by S. Karger AG, Basel } \\
\text { www.karger.com/crg }\end{array}$
\end{tabular}

Nakade et al.: A Case of Gastric Antral Vascular Ectasia Which Was Aggravated by Acid Reducer
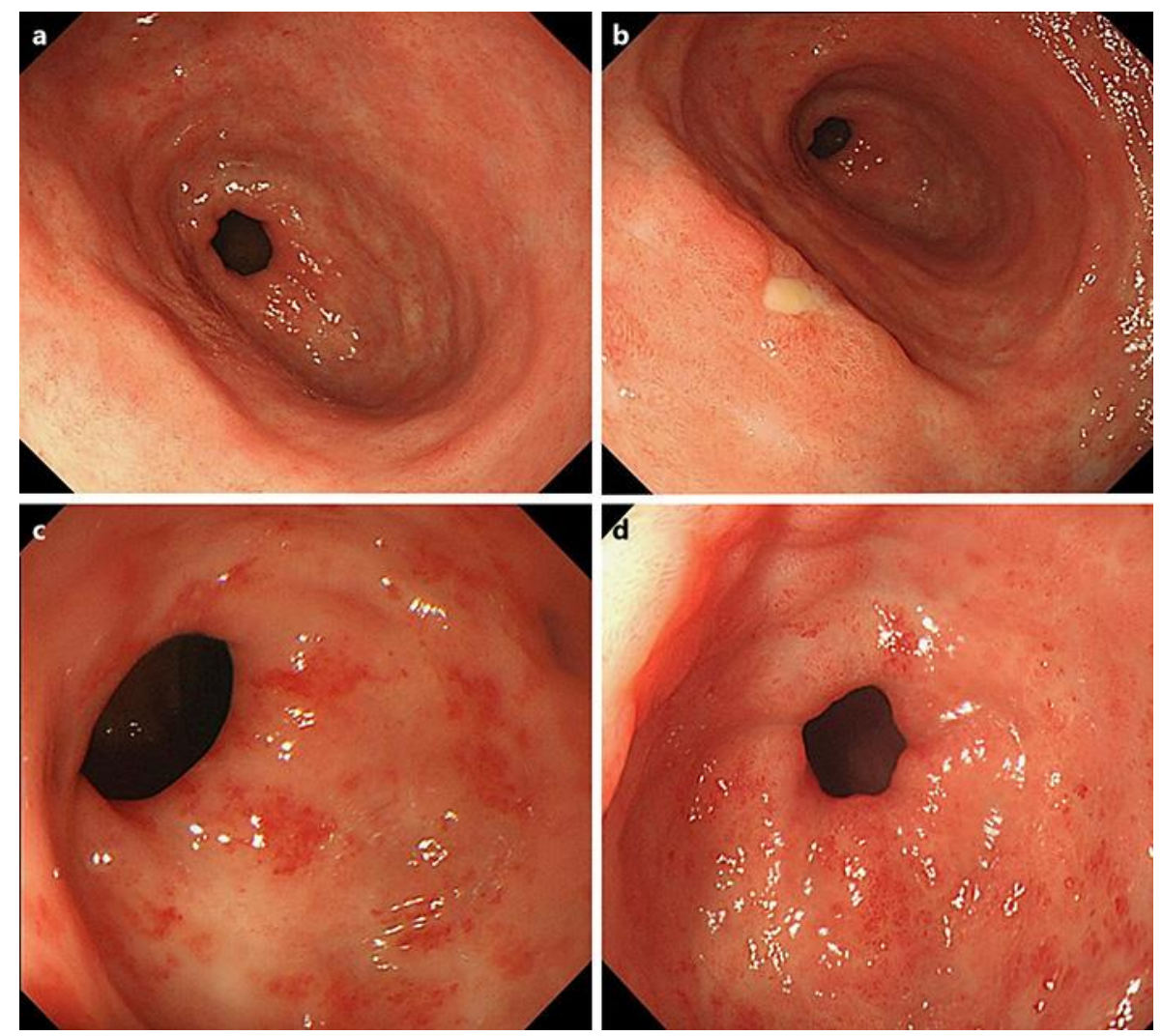

Fig. 3. a Endoscopic appearance showed that red patches or spots had improved in the antrum of the stomach. b Endoscopic appearance showed gastric ulcer emergence on the gastric angle of the greater curvature. c Endoscopic appearance revealed small and flat red spots in the antrum, and again diffuse oozing of blood. $\mathbf{d}$ Endoscopic appearance showed the classic "watermelon stomach" with columns of tortuous ectatic vessels attenuated in the antrum of the stomach. 


\section{Case Reports in Gastroenterology}

\begin{tabular}{l|l} 
DOI: $10.1159 / 000455967$ & C 2017 The Author(s). Published by S. Karger AG, Basel
\end{tabular} www.karger.com/crg

Nakade et al.: A Case of Gastric Antral Vascular Ectasia Which Was Aggravated by Acid

Reducer

Table 1. Laboratory data of the patient at admission

Laboratory data

Total protein, $\mathrm{g} / \mathrm{dL}$

Albumin, g/dL

Total bilirubin, $\mathrm{g} / \mathrm{dL}$

BUN, mg/dL

Creatinine, $\mathrm{mg} / \mathrm{dL}$

AST, IU/L

ALT, IU/L

ALP, IU/L

LDH, IU/L

$\gamma$-GTP, IU/L

Glucose, mg/dL

Total cholesterol, mg/dL

LDL cholesterol, mg/dL

Triglycerides, $\mathrm{mg} / \mathrm{dL}$

$\mathrm{Fe}, \mu \mathrm{g} / \mathrm{dL}$

Ferritin, $\mu \mathrm{g} / \mathrm{L}$

\begin{tabular}{lc}
\hline $\mathrm{WBC} / \mu \mathrm{L}$ & 6,300 \\
$\mathrm{RBC} / \mu \mathrm{L}$ & $2.0 \times 10^{6}$ \\
$\mathrm{Hb}, \mathrm{g} / \mathrm{dL}$ & 6.0 \\
$\mathrm{Ht}, \%$ & 18.6 \\
$\mathrm{Plt} / \mu \mathrm{L}$ & $14 \times 10^{4}$ \\
$\mathrm{PT} \%$ & 75 \\
$\mathrm{AFP}, \mathrm{ng} / \mathrm{dL}$ & 2.4 \\
$\mathrm{PIVKA}-\mathrm{II}, \mathrm{mAU} / \mathrm{mL}$ & 50 \\
$\mathrm{CEA}, \mathrm{ng} / \mathrm{mL}$ & 2 \\
$\mathrm{HBsAg}$ & - \\
$\mathrm{HBsAb}$ & - \\
$\mathrm{HBcAb}$ & - \\
$\mathrm{HCV} \mathrm{Ab}$ & +
\end{tabular}

45

3

10 